СAGUA yTERRITORIO

\title{
El sistema de abastecimiento del palacio de la Casa de Fernán Núñez, Córdoba (1679-1985)
}

\author{
The supply system of the palace of the House \\ of Fernán Núñez, Córdoba (1679-1985)
}

Francisco Manuel Espejo Jiménez Universidad de Córdoba Córdoba, España d52esjif@uco.es

\begin{abstract}
Resumen - El palacio de Fernán Núñez (Córdoba), al igual que los grandes conjuntos palatinos, contó con un sistema de abastecimiento que no solo suministró al inmueble y su jardín, sino que gracias a la eficaz recogida de aguas fue el motor de una serie de ingenios que se establecieron a partir de 1679. Esto se debió al interés de la Casa de Fernán Núñez por su gestión, pues de ella dependían todas las explotaciones locales y las buenas rentas que se obtenían. Gracias a las fuentes inéditas consultadas, al trabajo de campo realizado, entre otros, se ha podido reconstruir este sistema, en un cuestionado estado de conservación, con el fin de poner en valor la red que ha dado vida a la villa.
\end{abstract}

Abstract - The palace of Fernán Núñez (Córdoba), as well as the great palatine complexes, had a supply system that not only supplied the building and its garden, but thanks to the effective collection of water was the engine of a series of mills that were established from 1679. This was due to the interest of the House of Fernán Núñez for its management, since it depended on all local farms and the good rents that were obtained. Thanks to the unpublished sources consulted, the field work carried out, among others, has been able to reconstruct this system, in a questioned state of conservation, with the purpose of highlight the importance of the network that has given life to the town.

Palabras clave: Sistema de abastecimiento, Suministro hídrico del palacio, Casa de Fernán Núñez, Patrimonio hidráulico, Molinos de harina

Keywords: Supply system, Water supply of the palace, House of Fernán Núñez, Hydraulic heritage, flour mills

Información Artículo: $\quad$ Recibido: 11 diciembre 2018

Revisado: 11 agosto 2019

Aceptado: 26 octubre 2019 


\section{INTRODUCCIÓN ${ }^{1}$}

El término de Fernán Núñez (Córdoba) se caracteriza por la escasa presencia de recursos fluviales, siendo el arroyo Ventogil, de poca corriente, el más destacado ${ }^{2}$. Sus aguas proceden de varios manantiales que abastecen, a través de canalizaciones subterráneas, las fuentes locales ${ }^{3}$.

A pesar de esta carencia existió una importante red de ingenios hidráulicos desde finales del siglo XVII que tuvo su principio en el sistema de abastecimiento del palacio. Esto se debe a la tarea de dos figuras claves: el tercer y sexto condes de Fernán Núñez, entre los siglos XVII y XVIII. Como el caudal del arroyo Ventogil era insuficiente, el III conde unificó todas las aguas de distintas fuentes y manantiales, conduciéndolas para abastecer su palacio y aprovechar su desagüe para dar fuerza a unas industrias que había construido ${ }^{4}$. Su nieto, el VI conde, ampliaría y mejoraría dichos recursos ${ }^{5}$, dando lugar a un rico patrimonio hidráulico que se mantuvo en uso hasta bien entrado el siglo $\mathrm{XX}^{6}$.

Debido al lamentable estado de conservación del sistema de abastecimiento en la actualidad y a la importancia que tuvo para el antiguo mayorazgo, se hacía necesario un exhaustivo estudio que permitiera conocer su geografía física e histórica, el interés del agua para los condes y, sobre todo, sus rasgos históricos y físicos.

Este trabajo se encuadra dentro del área de geografía e historia y en él se ha seguido la metodología tradicional para su realización. Se ha comenzado con una recopilación de información a partir de una bibliografía local, las publicaciones ligadas a la Casa de Fernán Núñez y una amplia revisión de todos los archivos, especialmente el Fondo Palacio Ducal del Archivo Municipal y la Sección Nobleza del Archivo Histórico Nacional. Posteriormente ha tenido lugar el análisis de todas esas fuentes, apoyado con un profundo trabajo de campo.

El resultado de todo ello ha sido la presente síntesis. Con ella se ha podido determinar la singularidad de este sistema: Fernán Núñez, explotando sus acuíferos por falta de un curso fluvial importante, consiguió una gestión eficaz y sostenible del agua que fue el motor de la vida local durante más de 300 años. De este modo, se plantea su protección, precisando su propiedad y proponiendo su inclusión como Bien de Interés Cultural dentro del conjunto histórico-artístico del palacio.

\section{LA CASA DE FERNÁN NÚÑEZ: GEOGRAFÍA FÍSICA E HISTÓRICA}

El antiguo señorío de Fernán Núñez, hasta su disolución en el año $1982^{7}$, ocupó las $3 / 4$ partes del total de los 29,83 $\mathrm{km}^{2}$ que forman el término, localizado entre la Campiña Alta y Baja de Córdoba ${ }^{8}$. Gracias a la permeabilidad de su suelo, a diferencia del resto del territorio, hay una gran cantidad de aguas subterráneas

\footnotetext{
1 Ayuda FPU, Ministerio de Educación.

2 Jurado Miranda y otros, 2004, 35.

3 Naranjo Ramírez, 1991a, 19.

4 Crespín Cuesta, 1994, 121-122. Espinalt y García, 1787, XII, II, 14-15. Ramírez y Las Casas-Deza, 1986, 277. Sarazá Murcia, 1935, 221. Zurita, 1951.

${ }^{5}$ Crespín Cuesta, 1994, 131-133. Naranjo Ramírez, 1991a, 49-50.

${ }^{6}$ Crespín Cuesta, 1982, 91.

${ }^{7}$ Naranjo Ramírez, 1995, 139.

${ }^{8}$ Naranjo Ramírez, 1992, 163.
}

autoabasteciéndose en un 99\% actualmente en una población de casi 10.000 habitantes. El manto acuífero se localiza en la mitad sur de su término, por presencia del estrato de gravas calcáreas y arenas $^{9}$, correspondiendo con la zona más elevada, según se desprende de la investigación para el abastecimiento de la localidad de 1944 (Figura 1). Este tipo de tierras son las que aconsejaba Vitruvio ${ }^{10}$, ya en el siglo I a.C., para este fin.

La dirección de las aguas, por tanto, se orienta de sur a norte hacia el término municipal de Córdoba. Fernán Núñez, por consiguiente, se sitúa en la cuenca del río Guadalquivir, siendo la competencia de su gestión en la actualidad de la Confederación Hidrográfica del mismo río ${ }^{11}$.

Esta riqueza hídrica fue aprovechada desde la antigüedad romana pues en el siglo XVIII se hallaron algunas conducciones, entre otros restos arqueológicos, que estimaron la ubicación de la ciudad de Ulia en la villa $^{12}$, tal y como defendía Bartolomé Sánchez de Feria y Morales (1719-1783) ${ }^{13}$. Para ello se basaba en los restos localizados a oriente del término, circundando el pueblo por el mediodía hasta llegar a la población, a juzgar por la presencia de pozos profundos, arcos de ladrillo, albercas, fuentes como la de la Atalaya, etc., entre otras ruinas. Además, dentro del núcleo urbano había «cañerías de ladrillo, de pozo á pozo de las casas, donde se han hallado algunas inscripciones sueltas» y los restos de una antigua urbe que se prolongaba hasta poniente, en dirección a la ermita del Calvario ${ }^{14}$. Parte de estos hallazgos coinciden con el sistema de abastecimiento que se trata en este estudio.

Más adelante, entre 1905 y 1906, siguiendo los textos de Sánchez de Feria y Morales, el párroco Antonio Jurado realizó excavaciones en el ruedo de la población, especialmente en Mudapelo y Valdeconejos. En este último predio encontró una villa romana de importancia, decorada con esculturas, grandes mosaicos, una fuente de mármol labrada, entre otros, en un yacimiento que se estimaba de una extensión de un kilómetro cuadrado aproximadamente $^{15}$. La magnitud de la exploración conllevó la visita en 1907 del subdirector del Museo Arqueológico Nacional, Narciso Liñán Heredia ${ }^{16}$, institución en la que se encuentra depositado el mosaico del "Rapto de Europa” hallado en este lugar.

Plinio escribió en el siglo I d.C. que las aguas «dan origen a ciudades» ${ }^{17}$. Atendiendo a esta afirmación, estas infraestructuras hidráulicas pudieron ser el principio de ese emplazamiento. Crespín Cuesta ${ }^{18}$ insistía en que el origen del palacio se remontaba a una fortificación de esa época, de la cual queda el torreón inserto en el actual inmueble y una vieja canalización, descubierta en 1779, que surtía de agua a las fuentes del mismo.

\footnotetext{
9 Jurado Miranda y otros, 2004, 35. Naranjo Ramírez, 1991b, 31.

${ }^{10}$ Vitrubio, 1997, 194.

11 Jurado Miranda y otros, 2004, 33.

12 Sarazá Murcia, 1935, 217.

13 Sánchez de Feria y Morales, 1762, 231-233. 1772, IV, 373-374.

14 Ramírez de las Casas Deza, 1986, 279.

${ }^{15}$ Crespín Cuesta, inédito, 8-15 y 23-24.

${ }^{16}$ Crespín Cuesta, inédito, 26-30.

17 Plinio, 2002, 695

18 Crespín Cuesta, 1994, 24; 2007, 80.
} 


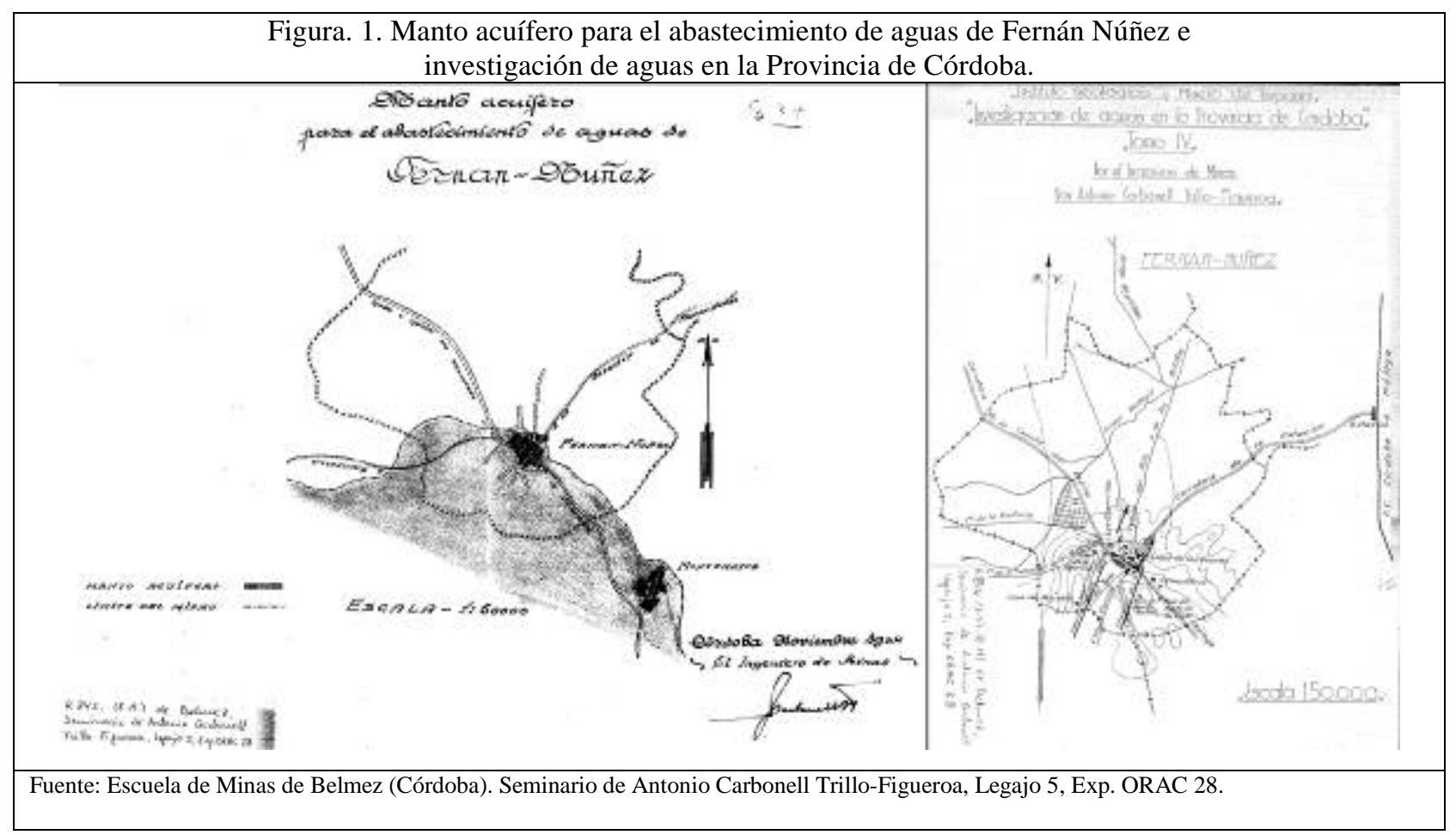

Sobre la calidad del agua del término se tiene constancia desde muy antiguo. En septiembre de 1707, por ejemplo, el médico Miguel de Castilla recomendaba distintos despachos de agua para la cura de diferentes enfermedades ${ }^{19}$. Por tanto, este elemento ha sido siempre muy importante para el municipio.

La propiedad del agua fue de la Casa de Fernán Núñez. El antiguo mayorazgo fue creado en 1382 gracias a Juan I de Castilla que concedió dicha facultad a doña Inés Alfonso de Montemayor y a su marido, Diego Gutiérrez de los Ríos. Su fundación se hizo en nombre de su primogénito e incluía "Montes é defesas, é heras, é exidos, é prados, é Aguas corrientes é non corrientes, é Molinos, é Fuentes é Pastos, é todas las otras cossas que á ello pertenecen é pertenezer deven [sic]", con la condición de que no podría venderlo ni enajenarlo hasta el postrimero de su linaje por siempre ${ }^{20}$.

Sería a partir del siglo XVII cuando este linaje y el municipio vivieron su momento de mayor esplendor. El 16 de abril de 1639 don Alonso Estacio Gutiérrez de los Ríos recibió el título de conde de Fernán Núñez ${ }^{21}$. Fue entre finales de esa centuria y el siglo XVIII cuando se produce el mayor cambio en el condado. Según Espinalt y García ${ }^{22}$ Francisco Gutiérrez de los Ríos (1644-1721), III conde, fue quien inició la transformación de la villa. Para ello instauró distintos establecimientos como hornos de pan, un mesón, molinos de harina y aceite y trajo

19 El agua es de la «Fuente Santa, que esta à la salida de la calle Sn. Marcos, camino del Calvario, en F. Núñez, cuia Agua servia de medicina para todo genero de enfermedades, como consta de certificación de Dn. Miguel de Castilla, medico revalidado [sic]». Archivo Histórico Nacional, Sección Nobleza (en adelante AHN-SN), Fernán Núñez, 964, 16.

Debía referirse al Pocito de Santa Marina, sito en este paraje, y famoso por sus propiedades curativas. Crespín Cuesta, 1982, 120.

${ }^{20}$ AHN-SN, Fernán Núñez, 1635, 27 y 13.

${ }^{21}$ Berni y Català, 1769, 324.

22 Espinalt y García, 1787, XII, II, 14-17. artesanos flamencos para sus fábricas de paños y seda. Asimismo, reunió las aguas y las distribuyó de tal forma que, además de dar fuerza a un batán, moverían una serie de molinos de harina y regarían finalmente varias huertas. Estos acontecimientos fueron también comentados por Zurita $^{23}$ quien añadía que estas obras se realizaron a instancias de Lorenzo de Villafranca, enviado por el aristócrata en calidad de gobernador y justicia mayor de la villa el 31 de mayo de 1701.

Estas mejoras conllevaron a un aumento considerable de la población en esta época ${ }^{24}$, por lo que era constante el intercambio de algunas propiedades en el ruedo de la villa para la construcción de viviendas debido al incremento de vecinos que estaba experimentando el señorío ${ }^{25}$. Esta sabia política sería continuada en la segunda mitad del siglo XVIII con Carlos José Gutiérrez de los Ríos (17421795), VI conde, que mejoró y aumentó dicho abastecimiento, aprovechando el descubrimiento de unas infraestructuras atribuidas a época romana ${ }^{26}$.

Los servicios prestados a la monarquía por su sucesor, Carlos Gutiérrez de los Ríos (1779-1822), fueron premiados con la concesión del título de duque el 23 de agosto de $1817^{27}$. De esta manera, la Casa de Fernán Núñez pasó a ser una de las más importantes del país, tal es así que en la segunda mitad del siglo XIX ocupaba la tercera posición como mayor contribuyente, conservando los primeros puestos aún en el siglo XX. La villa de Fernán Núñez, por su parte, comprendía el segundo lugar en obtención de rentas del ducado ${ }^{28}$. En este aspecto, el agua era imprescindible para el correcto funcionamiento

\footnotetext{
23 Zurita, 1951.

${ }^{24}$ Crespín Cuesta, 1994, 121.

${ }^{25}$ AHN-SN, Fernán Núñez, 478, 17 y 21.

${ }^{26}$ Espinalt y García, 1787, XII, II, 18. Ramírez y Las Casas-Deza, 1986, 280.

${ }^{27}$ AHN, Consejos, 2753, 1817.

${ }^{28}$ Artola Blanco, 2013.
} 
de las explotaciones. Por este motivo, y para determinar su propiedad, la III duquesa, María del Pilar Osorio y Gutiérrez de los Ríos, hizo escritura sobre el derecho de las aguas en su villa en 1911 alegando el antiguo privilegio de 1382. En el documento se declaraba propietaria del antiguo mayorazgo creado el 31 de mayo de 1420 (año 1382 de la era actual) incluyendo las aguas del término. Asimismo expresaba que la posesión tenía más de 100 años y que había sido disfrutada por todos los señores de su Casa, y que

"el acueducto mencionado, el agua con la construcción de mampostería que hay en el manantial, el cauce o cañería, los respiraderos y los registros, cajeros o alcubillas forman parte integrante de la casa-palacio con jardín descrita cuyo derecho confieren el artículo noventa y ocho de la vigente ley de aguas y el cuatrocientos ocho, en su párrafo último, del Código Civil”29.

Con ello dejaba claro que el agua no sólo era de su propiedad, sino que formaba una unidad con el palacio. El ayuntamiento de la localidad, en pleno de 8 de enero de 1911, reconoció dicho derecho ${ }^{30}$. Más tarde, en 1983, cuando su sucesora cedió por donación onerosa el inmueble manifestó en la escritura que junto a éste formaba parte un sistema de abastecimiento que venía de la estacada de la Peñuela y que nutría los cuatro estanques del jardín, además del resto de dependencias del conjunto palatino $^{31}$. Este suministro sería de especial importancia para la villa pues hasta 1965 el sistema de agua potable no llegó al servicio doméstico ${ }^{32}$. De hecho, fue en noviembre de 1967 cuando dicho palacio fue conectado a esta nueva red $^{33}$.

\section{LOS CONDES DE FERNÁN NÚÑEZ Y SU INTERÉS POR EL AGUA}

El III conde de Fernán Núñez comentaba en El Hombre Práctico que «...la arquitectura nos enseña tantos y tan admirables usos de las aguas, trayendo este elemento a nuestro servicio, y mandado, como lo vemos en los acueductos y molinos» ${ }^{34}$. Carlos José Gutiérrez de los Ríos (1742-1795), VI conde, continuó los intereses de su abuelo $^{35}$. En efecto, es posible reconocer ese incesante empeño a través de dos fuentes: por el contenido del Libro de Oro y Verdadero principio de la propia y ajena felicidad, donde expuso una serie de proyectos ${ }^{36}$ y consejos para la gestión hídrica ${ }^{37}$; y mediante lo que expresó Juan Valera en 1898, al comparar la política de

\footnotetext{
29 AHN-SN, Fernán Núñez, 2250, 5.

30 Crespín Cuesta, 1994, 334; 2007, 154-155.

31 Archivo Municipal de Fernán Núñez (en adelante AMFN), HC432.1.

32 Diago, 1965.

33 AMFN, Fondo Palacio Ducal, 48.

34 Ríos y Córdoba, 1680, 28.

35 Conde de Fernán Núñez, 1898, II, 409.

"él era sin duda el Hombre práctico que había dibujado con la pluma uno de sus inmediatos abuelos”. Labaig y Sabala, 1795, 20-21.

${ }^{36}$ Conde de Fernán Núñez, 1898, II, 384 y 395.

Según la edición de 1988 el Libro de oro y verdadero principio de la propia y ajena felicidad estaba inédito. Conde de Fernán Núñez, 1988 Nuestra indagación en los fondos sobre Fernán Núñez en distintos archivos no ha permitido encontrar el manuscrito. En dicho documento le habla a su primogénito de las mejoras y aumentos realizados en sus Estados y cómo manejarlos y seguir aumentándolos. En el momento de su muerte no lo había concluido. Archivo Histórico de Protocolos de Madrid (en adelante AHPM), T: 24836.

${ }^{37}$ Conde de Fernán Núñez, 1898, I, 266.
}

Carlos III en edificar monumentos, canales, caminos, fábricas, etc., con lo que realizó el conde en menor escala en el territorio de Fernán Núñez ${ }^{38}$, patrocinando diferentes obras y fundaciones ${ }^{39}$.

Igualmente sobresale en su obra Vida de Carlos III comentarios de mejora para algunas empresas de ingeniería hidráulica que el propio rey coordinó. Entre los ejemplos, tenemos el canal de Lorca y el canal de Madrid a Aranjuez hasta Alicante. En este último caso apuntó que hubiera sido más beneficioso conectar con el río Guadalquivir, ya que su conexión directa con el mar podía aumentar la mercancía y expansión de los productos españoles por el mundo ${ }^{40}$.

En una carta con el marqués de Uztáriz, intendente de Badajoz $^{41}$, le comunicaba que:

"la construcción de canales ocuparía gustosamente todo mi trabajo, sin aspirar a más premio que el de ver esculpido mi nombre en todas las obras de esta clase que dejase para la verdadera felicidad de España. Confieso que es la única ambición que me conozco [...]”42.

Esta obsesión por la ingeniería hidráulica se observa entre sus documentos. Los fondos son muy variados y lo mismo se interesaba por la calidad y uso del agua ${ }^{43}$, por los nuevos métodos para construir edificios -donde se incluían canales y estanques ${ }^{44}$-, o por la construcción de fortificaciones y baterías militares ${ }^{45}$. En este punto destacan proyectos de talla internacional, como el estudio del francés Martín de Labastide sobre el paso por el lago de Nicaragua para unir los océanos Atlántico y Pacífico, precedente del canal de Panamá, donde insertó al final un manuscrito propio ${ }^{46}$.

Asimismo, en sus constantes viajes hacía descripciones y dibujos de aquellas infraestructuras de este tipo que creía interesantes, como el aljibe del alcázar de Cáceres ${ }^{47}$, o planteaba baños como los de Ardales de Fuente Álamo ${ }^{48}$. Su conocimiento en esta materia lo debieron convertir en un referente, tanto que participó proporcionando una serie de instrumentos químicos e informes para la expedición de Alexandro Malaspina en su vuelta al mundo ${ }^{49}$.

Todos estos conocimientos, por tanto, fueron la base para explotar de la manera más práctica los recursos hídricos de su villa, como se ve continuación.

\footnotetext{
${ }^{38}$ Conde de Fernán Núñez, 1898, I, XV.

${ }^{39}$ Véase sobre ellas en: Vigara Zafra, 2015.

${ }^{40}$ Conde de Fernán Núñez, 1898, I, 265 y 384. Ibídem, II, 30-31.

${ }^{41}$ Éste fue maestro de Simón Bolívar. Cardozo Uzcátegui, 2011.

42 En carta del 11 de abril de 1780, desde Lisboa. BANC MS UCB 143, Vol. 151.

43 Véase: Principios elementares de química por d. Jose Ybenté, en AHN-SN, Fernán Núñez, 2039, 6.

O los libros de su colección como Gutiérrez de los Ríos, 1753 y Fernández, 1769.

44 Es un extracto del estudio de Loriot, partiendo de la observación de restos arqueológicos, sobre cómo hacían el mortero de cal y arena los romanos y que hacían mucho más sólidos y duraderos sus edificios. AHN-SN, Fernán Núñez, 87, 38.

45 BANC MS UCB 143, Vol. 1 y 2.

46 AHN-SN, Fernán Núñez, 2043, 10.

47 AHN-SN, Fernán Núñez, 2033, 6.

48 AHN-SN, Fernán Núñez, 2034, 3.

49 Archivo Museo Naval de Madrid (en adelante AMN), 0177, 0281/015; 0300; 0583/000; 0176, 0278/030; y 0176, 0278/023.
} 


\section{RASGOS HISTÓRICOS Y FÍSICOS DEL SISTEMA DE ABASTECIMIENTO}

Conocida la importancia del agua para la Casa de Fernán Núñez y aprovechando la cantidad y calidad de ésta en el subsuelo de su villa, se necesitaba de un medio que la explotara. Se creó, de este modo, toda una compleja infraestructura que convirtió al palacio de Fernán Núñez en el eje central de todo un sistema que se distribuía a lo largo de más de 3500 metros de longitud (Figura 2), y con un desnivel de 100 metros aproximadamente. Este edificio, por lo tanto, fue el fin de un sistema de abastecimiento compuesto de una extensa red de cañerías que tuvo su origen en un venero o manantial. A su vez, el inmueble fue el principio de una red de saneamiento o desabastecimiento que reciclaba el agua no sólo de este edificio principal, sino de todas las fuentes públicas anexas, convirtiéndose en motor de una serie de molinos de harina que se establecieron a partir de 1679, regando por último un cuidadoso número de huertas antes de desaguar en el arroyo Ventogil ${ }^{50}$.

El agua de manantial como fuerza motriz para molinos de harina, aunque era menos común que el empleo de los recursos fluviales, también se usó en Baeza ${ }^{51}$ o en Torremolinos $^{52}$. Aunque la mayoría de los veneros de la provincia de Córdoba nutrían las fuentes, pilares, lavaderos, etc. ${ }^{53}$, la peculiaridad de la red fernannuñense radica en que no sólo abastecía al palacio y sus fuentes, sino que reutilizaba su desagüe para la molienda e irrigación de una serie de plantíos.

El palacio contó, por tanto, con un sistema de abastecimiento como los grandes núcleos urbanos y conjuntos históricos de Andalucía. Sus ejemplos más cercanos se aprecian en los numerosos manantiales que surtían a la ciudad de Córdoba ${ }^{54}$, y sus grandes complejos como la mezquita ${ }^{55}$ o Madinat al-Zahra ${ }^{56}$. O bien, la Acequia Real en la Alhambra de Granada o los Caños de Carmona en los Reales Alcázares de Sevilla ${ }^{57}$.

El registro más antiguo de la conducción se encuentra en unos reparos en la cañería de la Peñuela o Valdeconejos en $1708^{58}$. En 1717, en la memoria de bienes del III conde se registraron unas casas con un batán de mano que había fabricado "en el sitio de la Cañeria a donde está el Arca del Agua de la Peñuela [sic]"59. Durante esta primera mitad del siglo XVIII tuvieron lugar distintas obras de mantenimiento que permiten conocer más detalles de la misma. Por ejemplo, en octubre de 1739 se recorre y se hace un pedazo nuevo, por su mal estado, de las canalizaciones inmediatas al nacimiento del agua ${ }^{60}$. $\mathrm{Y}$ gracias a un documento de 1741 se entiende que de dicha conducción venía el agua para los molinos de pan ${ }^{61}$

\footnotetext{
50 Espejo Jiménez, 2017.

51 Cruz Cabrera, 1996.

52 Heredia-Flores, 2013, 114.

53 Córdoba de la Llave y Castillo Pérez de Siles, 1999, 31.

54 Sánchez Trigueros, 2000, 11. López Amo, 1997.

55 Añón, Luengo y Luengo, 2000,16.

${ }^{56}$ Pizarro Berengena, 2012.

57 Añón, Luengo y Luengo, 2000, 16-17 y 38.

58 AMFN, Fondo Palacio Ducal, 2, PDC2.2.

59 Archivo Histórico Provincial de Córdoba (en adelante AHPCO), 11.892P.

60 AMFN, Fondo Palacio Ducal, 5, PDC5.1.

${ }^{61}$ AMFN, Fondo Palacio Ducal, 11, PDC11.2.
}

por lo que su fin único no era el suministro del conjunto palatino, sino aumentar el caudal de dichas infraestructuras. Tal es así que, por instrumento de 9 de diciembre de 1746, los arrendadores de los molinos estaban no solo obligados a limpiar sus atajeas, sino a soguear dichas cañerías, de manera que el agua se mantuviera corriente en todo momento. La Casa Señorial, por su parte, se hacía cargo de las reparaciones necesarias $^{62}$. Igualmente, en los arreglos de 1752 se reitera que dicha agua se conducía al jardín del palacio y a los molinos de pan del señorío ${ }^{63}$.

En 1779, durante la obra de composición de unas canalizaciones se descubrió una gran construcción que permitió ampliar el suministro ${ }^{64}$. Gracias al borrador con la descripción de la villa para su inclusión en el Atlante Español de Bernardo Espinalt, escrita por el administrador del conde Juan Castro ${ }^{65}$, se conocen más detalles. Para éste, el agua era

"de tan bello paladar que causan gusto a quantos la beben; [...] el venero de donde vienen esta agua es tan copioso, que en los años de más escazes en los pueblos inmediatos no ha hecho el mas lebe sentimiento.

[...] Este venero fue preciso recorrerlo en el año de 1779 y por su costosa y admirable fábrica se reconoció ser [...] de los Moros en España, y si con visos, de tiempo de romanos por aver encontrado en su obra alguna moneda de estos, i queriendo buscar el origen de su misma a costosa dilix. ${ }^{\mathrm{a}}$, por más que se hizieron, no se pudo encontrar, y si solo admirar lo grande y cuantioso de su obra, difícil de imitar en estos tiempos; infiriendose de esto y de las continuadas ruinas, zimientos [...], haver avido aquí alguna ciudad populosa que según juicio critico e histórico se presume aver sido, aquella tan memorable por lo grande que entre todas merecio el renombre de Gran Ulia [sic]" ${ }^{\text {66 }}$.

En relación con esto, Carlos José Gutiérrez de los Ríos le comunicaba a su hijo que había mejorado dichos recursos, poniendo en uso antiguas cañerías, y le recomendaba continuar descubriendo y explotando nuevos manantiales debido a la abundancia de agua en el señorío ${ }^{67}$.

Efectivamente, estas mejoras son visibles en los planos identificados en la fundación Biblioteca Manuel Ruiz Luque en Montilla ${ }^{68}$. Destacan varias acuarelas realizadas entre 1776 y 1779 por Joaquín de Luna. Una de ellas representa la canalización de la estacada de Los Almendrales hacia el molino de la fuente, anexo al palacio, así como la mina del mismo pago (Figura 3 y 4). Sin embargo, no se han encontrado restos de dicha red ni registro de su construcción en las cuentas del archivo. Sí se aprecia que se cruzaba con la cañería del palacio y que se comunicaba con el ramo de la mina de San Sebastián, cuyos trabajos de descubrimiento comenzaron el 22 de septiembre de 1776 y se extendieron hasta el 17 de agosto de $1777^{69}$.

\footnotetext{
62 AMFN, Fondo Palacio Ducal, 56, PDC56.1.

63 AMFN, Fondo Palacio Ducal, 10, PDC10.1.

64 Espinalt y García, 1787, XII, II, 18. Ramírez y Las Casas-Deza, 1986, 280.

65 Conde de Fernán Núñez, 1898, II, 383.

${ }^{66}$ AHN-SN, Fernán Núñez, 184, 17.

${ }^{67}$ Conde de Fernán Núñez, 1898, II, 396.

${ }^{68}$ Fundación Biblioteca Manuel Ruiz Luque, MS-87.

${ }^{69}$ AMFN, Fondo Palacio Ducal, 33, PDC33.1. 33, PDC33.2.
} 
Figura 2. Detalle del sistema de abastecimiento y desabastecimiento de aguas del ducado de Fernán Núñez.
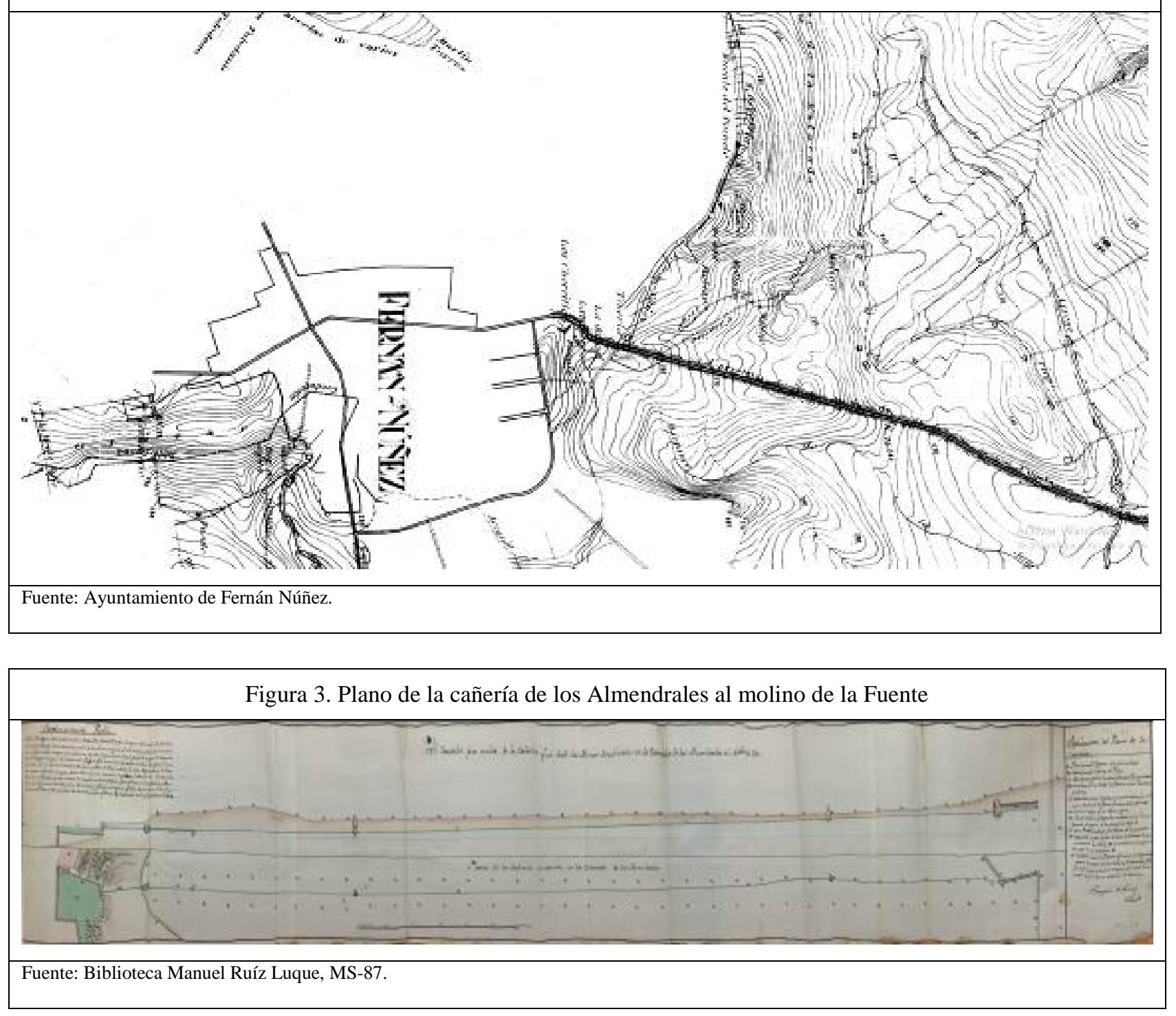

Figura. 4 y 5. Plano de la mina de la Estacada de los Almendrales y Explicación del plano de la Fuente de la Atalaya
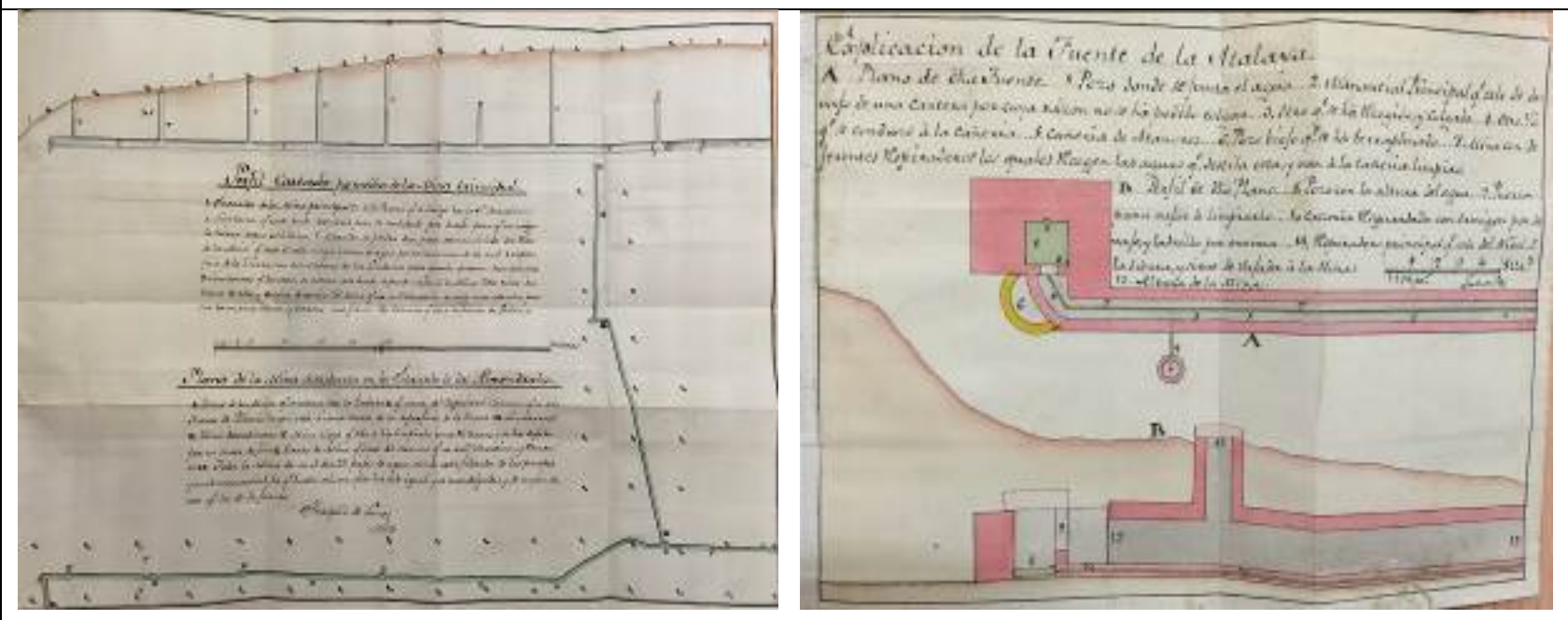

Fuente: Biblioteca Manuel Ruíz Luque, MS-87. 


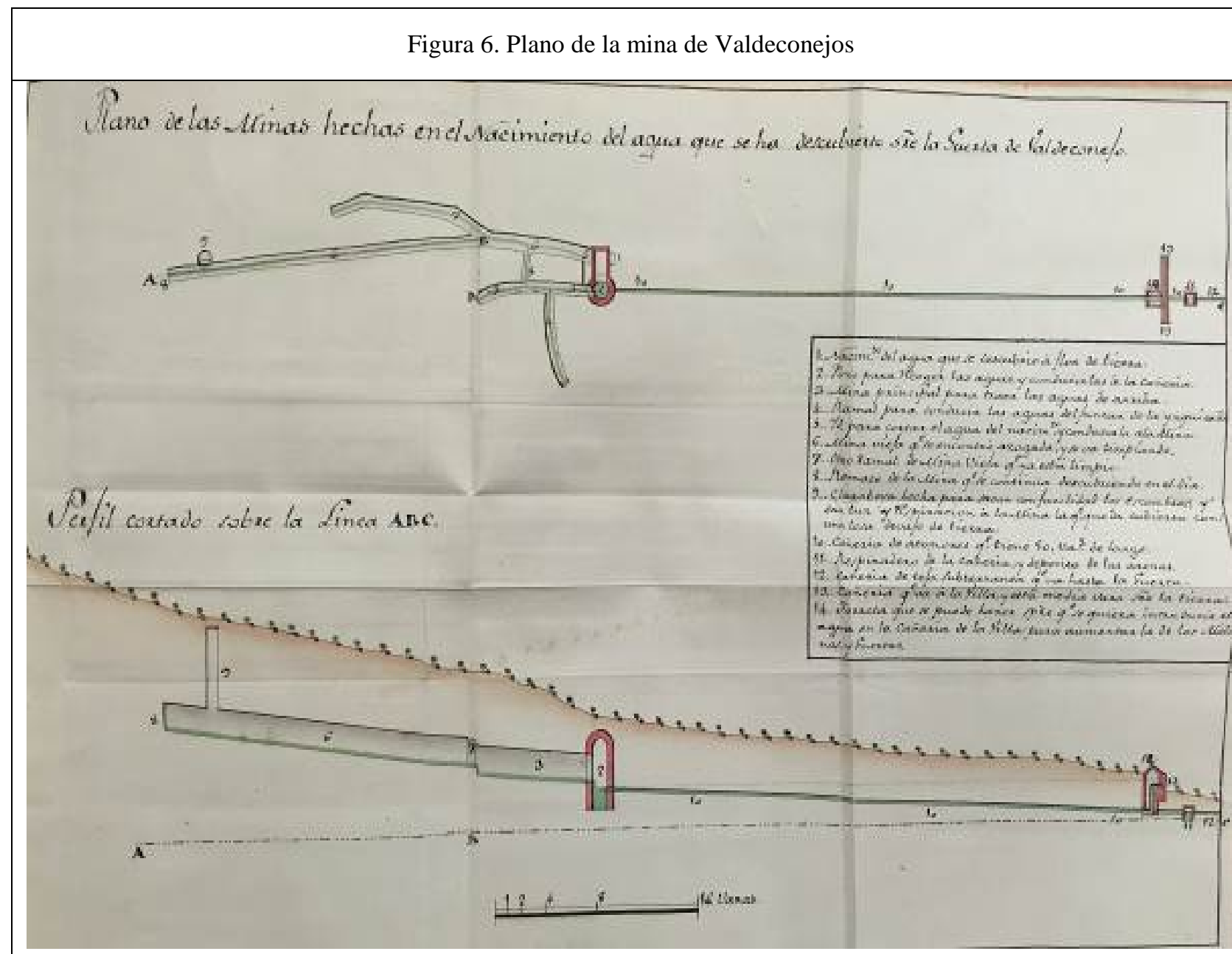

Fuente: Biblioteca Manuel Ruíz Luque, MS-87.

Por otro lado, se esbozó la desaparecida fuente de la Atalaya (Figura 5), cuyo descubrimiento comenzó el 26 de noviembre de $1775^{70}$ finalizando las distintas tareas en torno al 19 de mayo de 1776 con la ejecución del estanque $^{71}$

Por último, está el plano de la mina de Valdeconejos (Figura 6) que forma parte del sistema de abastecimiento del palacio. Éste, como se describe a continuación, estaba compuesto por un venero de agua y una cañería provista de una arquería y distintos registros y respiraderos hasta llegar al propio inmueble.

\section{EL VENERO 0 "ARQUITA DEL AGUA"}

Siguiendo el método histórico y geográfico tradicional, y gracias a la documentación inédita consultada y al trabajo de campo realizado a partir del Itinerario de la canalización subterránea de las aguas propiedad de la Casa Ducal (Figura 7), hemos podido localizar el principio de todo el sistema en un antiguo venero conocido como "Arquita del agua"- a unos 324 m.s.n.m. (Figura 8 y 9), en la mencionada estacada de la Peñuela perteneciente al antiguo pago de Valdeconejos (sureste del término: $37^{\circ} 39^{\prime} 44,62^{\prime}$ N, $4^{\circ} 42^{\prime} 25,77^{\prime}$ 'W).

La orografía y humedad del terreno indica que el asentamiento donde se ubica es el lugar que desecó el VI

\footnotetext{
${ }^{70}$ AMFN, Fondo Palacio Ducal, 32, PDC32.1.

${ }^{71}$ AMFN, Fondo Palacio Ducal, 33, PDC33.1; 24, PDC24.2.
}

conde en dicho pago. En 1779, cuando se estaban componiendo las cañerías, se encontró que la principal de ellas era una gran obra estimada en época romana, aumentándose con ello el caudal a la vez que se iban buscando y habilitando otros manantiales ${ }^{72}$. Su administrador, Joaquín de Luna, pudo tomar su agua para conducirla al palacio sin ninguna oposición ${ }^{73}$.

Sobre esa fecha se realizó un plano con las minas descubiertas en Valdeconejos (Figura 6). Según el esbozo, se pretendían unificar varias de ellas, aprovechando la vieja canalización y descubriendo otras nuevas. Por el texto se aprecia que era un proyecto de intenciones aún no concluidas y que además de conectarse a la cañería de la villa, su agua servía para aumentar el caudal para los molinos y huertas.

Las cuentas estudiadas transmiten que las obras en este pago comenzaron el 12 de mayo de 1776. Entre esa fecha y el 22 de septiembre se relacionan distintos gastos en las atajeas de la huerta de este sitio y en la cañería que de aquí iba al palacio ${ }^{74}$; mientras que entre el 6 de marzo y el 17 de abril de 1779 se construyó una alberca para la misma huerta $^{75}$

\footnotetext{
72 Espinalt y García, 1787, XII, II, 16 y 18.

73 AHN-SN, Fernán Núñez, 2250, 5.

74 AMFN, Fondo Palacio Ducal, 33, PDC33.1.

75 AMFN, Fondo Palacio Ducal, 37, PDC37.1.
} 
Figura 7. Itinerario de la canalización subterránea de las aguas propiedad de la Casa Ducal y aguas de Fernán Núñez

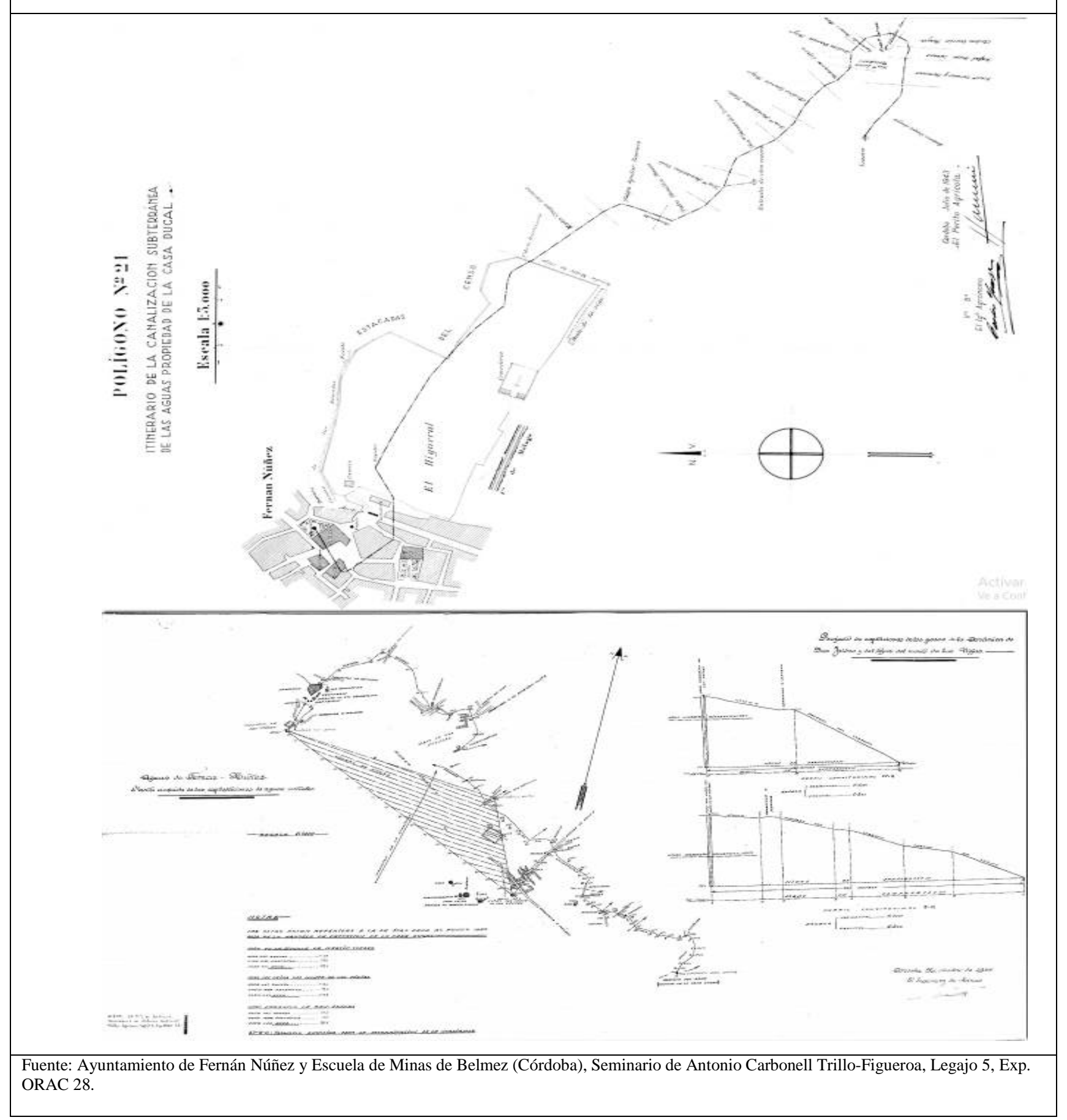

Fue en el año de 1907, al descubrirse el yacimiento arqueológico de Valdeconejos, cuando se observó dicha “Arquita del agua” y se escribió que estaba

"Bajando de la loma de Valdeconejos al pequeño valle que forma con las adyacentes, siempre hacia la parte oriental, se ve una especie de bóveda de dos metros de altura en forma de pirámide truncada, con una gran abertura en la parte superior, por donde pueden observarse las dos galerías que a sus lados corren" ${ }^{76}$.

El estudio a pie de terreno ha permitido su hallazgo en la actualidad. En su origen, según los fondos consultados, el venero se presentaba como una corriente que afloraba a

\footnotetext{
${ }^{76}$ Liñán y Heredia, 1907, 407.
}

la superficie de forma natural y se cubría con una alcubilla o arca en forma de pirámide, expulsando un caudal de 4 litros por segundo ${ }^{77}$. Este sistema de captación, común desde la época romana, se va a dar en la provincia de Córdoba, observándose un modelo próximo en la alcuba que hay junto a la fuente de El Cañuelo de Montemayor ${ }^{78}$.

Actualmente se presenta hundida, sin agua y en mal estado de conservación. Sus características, similares al esquema de Pseudo-Juanelo para este tipo de construcciones $^{79}$, son las de la anterior descripción: una

\footnotetext{
77 AHN-SN, Fernán Núñez, 2250, 5.

78 Córdoba de la Llave y Castillo Pérez de Siles, 1999, 30.

${ }^{79}$ Pseudo-Juanelo Turriano, 1983.
} 
Figura. 8. Estado actual de conservación de la “Arquita del Agua” (A), alberca en el nivel inferior inmediato a la arquita (B), arquería (C) y registro del agua en el mesón (D).
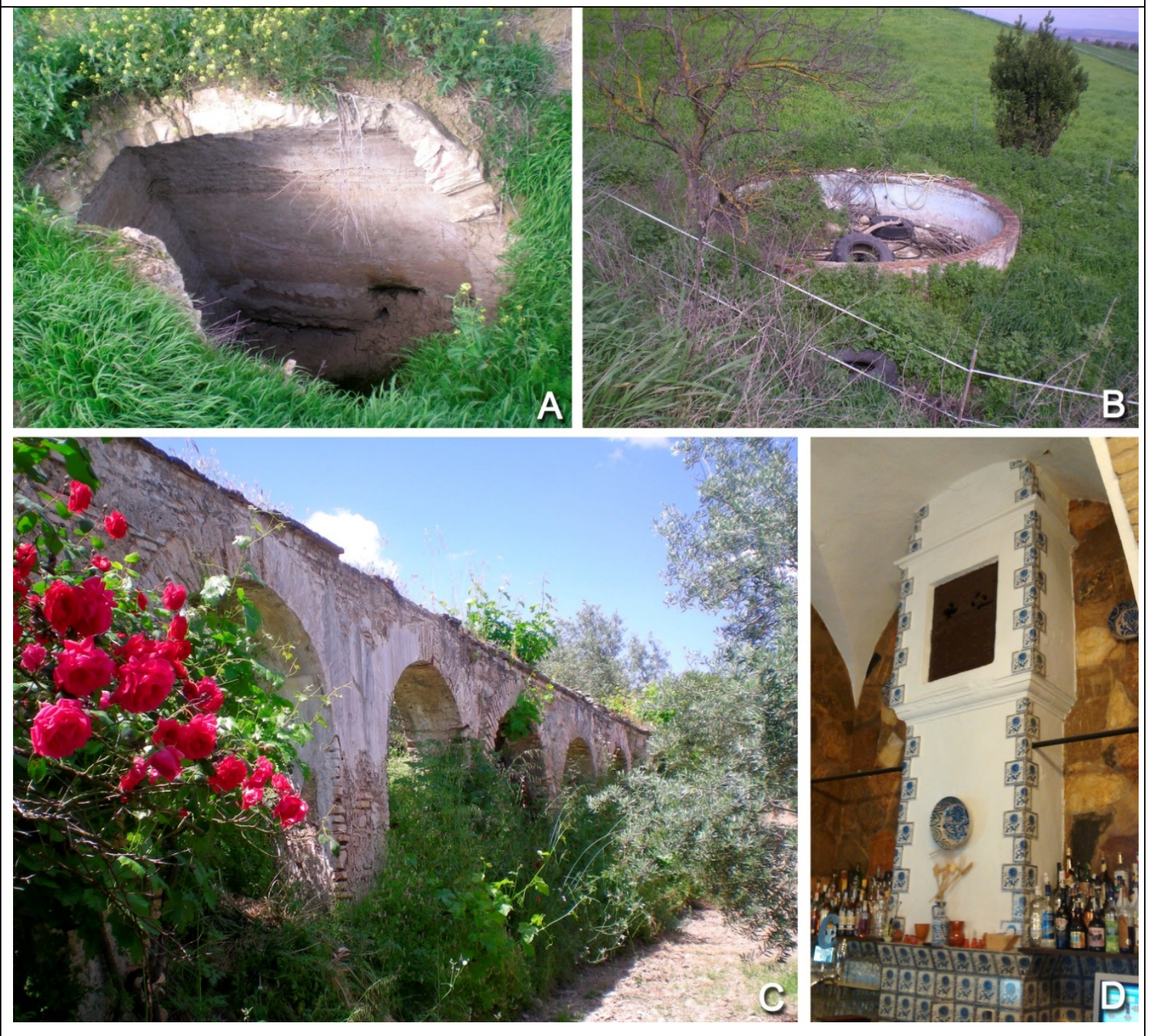

Fuente: Foto propia.

bóveda soterrada de 2 metros de altura con una planta de 2,5 metros. En sus muros se observan 3 orificios, a ras de suelo, dos de iguales dimensiones en los laterales para la captación del agua y una tercera apertura de mayor tamaño en el extremo inferior que debía estar conectada a la cañería de distribución. Según Córdoba de la Llave y Castillo Pérez de Siles ${ }^{80}$ estas aperturas laterales servían para aumentar el caudal aprovechando filtraciones cercanas. Asimismo, debió disponer de una puerta para tomar agua de su interior y hacer las labores de limpieza y mantenimiento.

Esta infraestructura está realizada en ladrillo, en su mayoría, con grandes sillares de caliza en su base. Se cubría con un enfoscado tanto en la parte interior como exterior. Las dimensiones de dichos ladrillos (315 por 155 por $55 \mathrm{~mm}$.) siguen la medida del ladrillo romano de un pie, muy común en los yacimientos cercanos de la

\footnotetext{
${ }^{80}$ Córdoba de la Llave y Castillo Pérez de Siles, 1999, 30.
}

Campiña ${ }^{81}$. Además, como dato interesante, son similares a los empleados en la construcción del palacio ${ }^{82}$ así como a los del resto de obras de la cañería, lo que demuestran la unicidad del conjunto hidráulico que, aunque pudo tener un origen anterior, se adapta en el siglo XVIII a las nuevas necesidades de la época.

\section{LA CAÑERÍA}

A partir del arca el agua era conducida por arcaduces o atanores de barro. Este sistema sigue el ejemplo descrito por Vitrubio ${ }^{83}$ y Pseudo Juanelo y recomendado por mayor salubridad. Los distintos atanores se unían con zulaque, que es un mortero de cal viva mezclado con aceite, entre otros compuestos ${ }^{84}$. Entre la correspondencia informativa sobre obras en el archivo se conserva un

\footnotetext{
${ }^{81}$ Lacort Navarro, 1985, 366-367 y 370-371.

${ }^{82}$ AMFN, HC-736.4.

83 Vitrubio, 1997, 214 y 215

84 Pseudo-Juanelo Turriano, 1983, 128 y 138.
} 
documento de 1808 en el que un maestro alfarero de La Carlota se ofrece para

“[...] hacer los caños que se necesiten para la fontaneria de media vara de largo, y a dos rr. cada uno, para lo qual me ha presentado una muestra de buena calidad, y en virtud de que la fontaneria que conduce las aguas a las fuentes de la Plaza de Palacio y Jardin de V.E. hay que hacer todos los años doce ú mas composiciones, lo uno por estar su cañeria casi en la superficie de la tierra, y lo otro rotos los mas de sus caños por las continuas composiciones que ha sufrido, en donde no se ha hecho mas que tapar con Zulaque sus roturas, me parece muy conveniente a los intereses de V.E. se hiciese una porcion de dichos caños y se fuesen reponiendo todos los que están quebrados; con lo q.e se remediaba el continuo censo perpetuo como se ha pagado al año por dichas composiciones: p.r lo que espero se sirva V.E. determinar lo que fuere su mayor agrado en este particular [sic]"85.

La conducción, en su mayor parte como se verá, discurría de manera subterránea en forma de galería. Según la Figura 4 tenía una profundidad de 5 varas (menos, como se ha visto, en torno al palacio) para la mayor protección y frescor del agua, así como de raíces y labores agrícolas ${ }^{86}$. Córdoba de la Llave y Castillo Pérez de Siles ${ }^{87}$ comentan que estas infraestructuras frecuentaban tener la altura de un hombre y estaban cubiertas con bóveda de medio cañón.

Los atanores se debían disponer en el interior de una atajea o caja de ladrillo, como se observará en la arquería, con una anchura de unos 62 centímetros. Era común que la tubería resultante se protegiera con mortero, manteniéndose la técnica de época romana y medieval ${ }^{88}$. En Córdoba capital no se tiene constancia de este tipo de caños insertos en cajas de ladrillo, aunque sí se han observado en Sevilla ${ }^{89}$.

A través de esta conducción, el agua se distribuía por gravedad, sistema que mantienen los actuales depósitos municipales ${ }^{90}$. La cañería discurría por una serie de fincas de propiedad particular, siguiendo el mencionado Itinerario de la Canalización Subterránea de las Aguas Propiedad de la Casa Ducal (Figura 7). Según las escrituras sobre el derecho de aguas de $1911^{11}$, esta infraestructura atravesaba 20 posesiones. Comenzaba en la estacada de olivar donde radicaba el manantial productor del agua, al término de la cual existía un cajero o alcubilla. En la actualidad, se encuentra una alberca de planta circular de 6 metros de diámetro aproximadamente (Figura 8 y 9) y que se usaba para regadío ${ }^{92}$, aunque carece de agua.

Desde aquí continuaba por otras fincas, siendo en la octava propiedad o estacada de olivar llamada Cañadas donde, en mitad de la posesión, había un registro o alcubilla, no volviendo a aflorar nuevamente en la superficie hasta la décima posesión. Trazando una línea longitudinal sobre esta última, a los 33 metros aproximadamente, había un respiradero de mampostería

\footnotetext{
85 AHN-SN, Fernán Núñez, 495, 1, 67 y 68.

${ }^{86}$ Pseudo-Juanelo Turriano, 1983, 155.

${ }^{87}$ Córdoba de la Llave y Castillo Pérez de Siles, 1999, 31-33.

${ }^{88}$ Córdoba de la Llave y Castillo Pérez de Siles, 32-33.

89 Pizarro Berengena, 2012, 246.

90 Jurado Miranda y otros, 2004, 126-127.

91 AHN-SN, Fernán Núñez, 2250, 5.

92 Marín Almenara y Molero Berral, 1992, 80.
}

que sobresalía un metro sobre el terreno. Tenía forma de paralelepípedo acabado en pirámide y cada una de sus caras medía medio metro. Otro similar volvería a estar presente a los 89 metros de entrada en la duodécima propiedad nombrada Huertezuela ${ }^{93}$.

\section{LA ARQUERÍA}

El punto más interesante se encuentra en la posesión décimo tercera, conocida como Los Arcos. Aquí la cañería atravesaba la finca a lo largo de 93 metros y al final de la misma existía otra alcubilla ${ }^{94}$. En esta posesión, con el fin de salvar el desnivel que se produce en el terreno causado por el arroyo Huertezuela, es donde la cañería pasa a la superficie sostenida por arcuationes o arquerías (Figura 8 y 9) y motivo por el cual el espacio se conoce como Los Arcos.

Dicha estructura se menciona por primera vez en un reparo de $1769^{95}$. Popularmente se ha desconocido su uso y se le ha atribuido un origen romano e incluso árabe ${ }^{96}$. En la bibliografía consultada no se han observado construcciones similares en la comarca, aunque su técnica edilicia, en mampostería y ladrillo, sí se aproxima a los arcos que forman el camarín de la parroquia de Santa Marina de Aguas Santas en la calleja de los Arcos, de la primera mitad del siglo XVIII. Además, los ladrillos de todos estos inmuebles mantienen las mismas dimensiones que los observados en el venero.

La arquería tiene una longitud de 65,90 metros aproximadamente y está a una altura de 315 m.s.n.m. Consta de 29 arcos, más estrechos en los extremos y semienterreados, con un ancho superior de unos 62 centímetros, mientras que la amplitud de las arcadas y los pilares son irregulares, siguiendo un orden creciente desde los extremos al centro del conjunto. Igualmente, los arcos, de medio punto, varían su intercolumnio desde los 80 hasta los 200 centímetros en el punto central, alcanzando una altura de 3 metros.

Los cimientos, por otro lado, son de caliza sobre los que se desarrollan las arquerías en ladrillo y los paños de mampuesto con cal y arena. La parte superior, por donde se conducía el agua, se remata con una caja de ladrillo o atajea compuesta por cinco hiladas de ladrillo y una $6^{\text {a }}$ en voladizo. Toda la infraestructura, por los restos encontrados, estaba enfoscada con mortero de cal y arena y encalada.

Según la documentación ${ }^{97}$ se especifica que en esta propiedad, junto al camino de Los Almendrales, había un venero de unas dos pajas de agua que se conectaba a la última alcubilla por una cañería que atravesaba la finca a lo largo de cuarenta metros. Este manantial podría ser aquel que aparece como «Entrada de otro venero» en el Itinerario de la Canalización Subterránea de las Aguas Propiedad de la Casa Ducal o como "galería» ${ }^{98}$ en la Planta acotada de las explotaciones de aguas actuales de

\footnotetext{
93 AHN-SN, Fernán Núñez, 2250, 5.

94 AHN-SN, Fernán Núñez, 2250, 5.

95 “la cañería de los Arcos”. AMFN, Fondo Palacio Ducal, 23.

96 AA.VV., 1992, 608. Jurado Miranda y otros, 2004, 99.

97 AHN-SN, Fernán Núñez, 2250, 5.

${ }^{98}$ A pie de terreno y gracias al servicio de aguas del Ayuntamiento de Fernán Núñez se ha podido constatar que este manantial se corresponde con la entrada que había antiguamente de un venero en la parte superior del sitio de la Huertezuela y que hoy está perdido.
} 


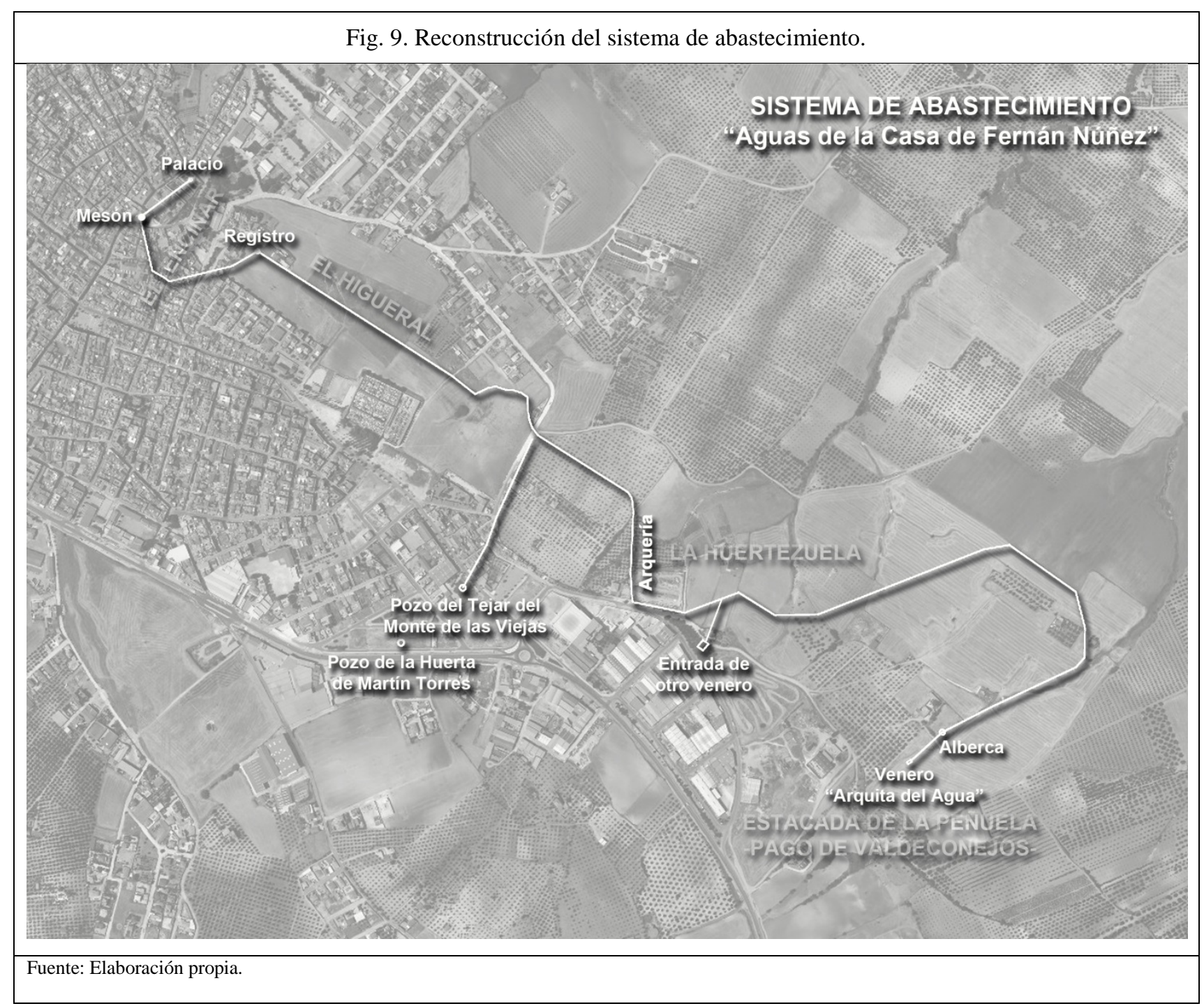

1944 (Figura 7) de la que se desprende la presencia, más adelante, de otros dos pozos de captación denominados «Pozo de la Huerta de Martín Torres» y «Pozo del Tejar Monte de las Viejas», aunque se desconoce si estos últimos estuvieron vinculados para aumentar el caudal.

FINAL DE LA CAÑERÍA

Continuando con el expresado itinerario, la última posesión que atravesaba la canalización, antes de penetrar en el espacio urbano, era la suerte de estacada conocida como Castillo, siendo la parcela más amplia y donde la infraestructura manifestaba la mayor extensión (Figura 7 y 9). Se trataba del olivar de El Higueral donde en su parte media había "un respiradero de mampostería en forma de paralelepípedo terminado por pirámide de medio metro de altura desde la superficie del terreno, siendo también de cincuenta centímetros la latitud de las caras o lados" ${ }^{99}$.

La presencia de esta construcción en esta finca y la necesidad de su conservación se manifiestan de manera constante a lo largo de la historia local, más aún por ser un espacio colindante con el casco de la población, en concreto, con la barriada de El Encinar ${ }^{100}$. Por ejemplo, la

\footnotetext{
99 AHN-SN, Fernán Núñez, 2250, 5.

100 La tradición popular manifiesta la presencia de una galería, de un hombre de alto, en este territorio. Junto a ella, a unos metros, se dispone una moderna red de saneamiento y la conducción que
}

construcción en 1822 de unas prensas de aceituna en este lugar hizo necesario abrir un pozo de agua, pero preocupaba su realización, por lo que fue necesaria una inspección para determinar que no afectaba a la cañería ${ }^{101}$. Algo parecido ocurrió en 1934, cuando la Casa Ducal estaba reparando la infraestructura sin licencia y tenía intención de reconducirla a otro lugar, afectando la integridad de las viviendas. El motivo fue el deterioro del muro por donde se conducía el agua hacia el lavadero nombrado "La Cañería”, que era de la Casa. Con las filtraciones, además de dañarse, no podía contener el talud en que se encontraba y su desmoronamiento suponía la destrucción de la canalización de aguas. El litigio se resolvió finalmente eliminando el lavadero para evitar la reconducción ${ }^{102}$.

Ya dentro del casco urbano, y a la espalda de la calle El Encinar, dicha conducción atravesaba, a lo largo de quince metros y medio, la mitad de la casa número 38 de la calle El Arenal. Después discurría, durante 12 metros, la casa número 18 de la misma vía ${ }^{103}$.

conduce el agua de la mina de El Higueral o San Sebastián hasta otras fuentes.

101 AHN-SN, Fernán Núñez, 356, 12, 9.

102 Crespín Cuesta, 2007, 147-149.

103 AHN-SN, Fernán Núñez, 2250, 5. 
En este punto es interesante resaltar que no sólo era útil para el abastecimiento del palacio sino que, aun cuando no existía la red de agua potable local, los vecinos del lado impar de esa calle se surtían a través de alcubillas. Del mismo modo, aunque en el documento de 1911 no se declara tal cesión, según Crespín Cuesta tenían acceso a ella las casas de la calleja de los Arcos y, por debajo del palacio, los vecinos de la calle de Los Espejos ${ }^{104}$. Probablemente, por la invasión de viviendas particulares y las molestias que pudiera causar la canalización, la Casa Ducal accediera a este préstamo. A este respecto, en uno de los libros de la biblioteca del VI conde se expresa que era habitual que quien necesitaba agua podía acordar con el vecino, bien altruistamente o bajo precio, su paso comprometiéndose con los arreglos necesarios. O bien, los vecinos podían tener por convenio una arquilla con su marco inmediata al surtidor, muchas veces medianera entre dos casas ${ }^{105}$.

A continuación, antes de llegar al palacio, la cañería atravesaba varios inmuebles de la calle Beneficiado (hoy calleja de los Arcos), en concreto las viviendas número 19 y 17, esta última a lo largo de 13 metros. Finalmente llegaba a la vigésima o última posesión, que se correspondía con el número 39 de la calle Rosales (hoy La Feria) donde había un cajero o alcubilla ${ }^{106}$.

En esta finca se halla el mesón, una de las dependencias anexas al palacio. Aún hoy se haya aquí la antigua captación de agua (Figura 8 y 9) para el servicio de este establecimiento, aunque sin uso, y que se correspondería con dicho cajero. Se trata de un arca aérea, es decir, una alcubilla que sobresale del nivel del suelo a modo de pilar y que en su parte superior dispone de una puerta de acceso. Las arcas de este tipo solían poseer una caldera de bronce en la parte alta para distribuir el agua. Aunque la de la Casa de Fernán Núñez es interna, en Córdoba se situaban en plena calle como las que había frente al convento de Santa Clara, el Campo de la Merced o la plaza de Jerónimo Páez, o bien como la conservada junto al muro norte del patio de los Naranjos de la mezquita $^{107}$.

En el "Aprecio de alpatanas de fincas y los inventarios de la tercia” o mesón aparecía una escalera pequeña para la alcubilla ${ }^{108}$, lo que confirma la existencia de esta arca aérea. Además, una de las cláusulas de la escritura de arrendamiento de este establecimiento expresaba que la Casa Ducal se reservaba el derecho de acceso al inmueble con el fin de inspeccionar el indicado registro de agua y la cañería $^{109}$.

El abastecimiento de agua al mesón también aparece en el citado borrador con la descripción de Fernán Núñez para Espinalt y García ${ }^{110}$. Este escrito, aunque alude al arca estudiada, hace también referencia a una antigua fuente situada en el centro de la plaza del palacio que permaneció hasta la transformación del nuevo conjunto a partir de 1783.

\footnotetext{
104 Crespín Cuesta, 1982, 87; 2007, 43.

105 Ardemans, 1724, 143-144.

106 AHN-SN, Fernán Núñez, 2250, 5.

107 Pizarro Berengena, 2012, 280, 282, 292, 327 y 328.

108 AMFN, Fondo Palacio Ducal, 6.

109 AMFN, Fondo Palacio Ducal, 3.

${ }^{110}$ AHN-SN, Fernán Núñez, 184, 17.
}

Ya en este lugar, la cañería se introducía perpendicularmente por debajo de la fachada del palacio en dirección al jardín, tal y como se observa en el itinerario, siguiendo una pendiente decreciente.

Como expresaba Vitrubio ${ }^{111}$ las aguas, al llegar a su destino, se almacenaban en un aljibe para su consumo y distribución. Para Pseudo-Juanelo ${ }^{112}$ este depósito se realizaba dentro de las fortalezas de los grandes señores. Podía construirse bien cavado en el suelo como pozo o encima, cubierto de bóveda. Sin embargo, aunque no se descarta, se desconoce la existencia de este tipo de infraestructura en el palacio, ya que no se ha encontrado la boca de acceso ${ }^{113}$.

Gracias a esta red hidráulica las aguas discurrían hasta dicho edificio, a una altura de 300 m.s.n.m., donde se formaban varias fuentes. Su inspección, vigilancia y reparación era por cuenta de la Casa Ducal hasta 1983, cuando se donó, como se dijo anteriormente, junto al palacio pasando a ser competencia municipal.

En total, según el documento analizado ${ }^{114}$ habría inscritos un total de 1.417 metros de canalización, además de 3 registros y 2 respiraderos. A ello habría que añadir la entrada de otros veneros aparte del trazado que discurre por caminos, calles, etc., o el propio palacio hasta llegar al jardín.

Mediante estos pozos de registro, actualmente desaparecidos, se tenía acceso a la galería. Su construcción, volviendo a Vitrubio ${ }^{115}$ y Pseudo-Juanelo ${ }^{116}$, se recomendaba a intervalos para que en caso de avería se tuviera mejor acceso al punto de rotura y no hubiera que levantar toda la infraestructura. Los respiraderos o aliviaderos, por su parte, servían para liberar la presión del aire.

Dichos registros, denominados también lumbreras, eran construcciones verticales que afloraban a la superficie ${ }^{117}$ y sus cubiertas recibían el nombre de "tientos y tantos"118. Los citados anteriormente estaban realizados en mampostería con forma de paralelepípedo alcanzando una altura de medio metro ${ }^{119}$.

Por su parte, tradicionalmente el trazado de las cañerías solía seguir el mismo de las calles, tal y como se observa en Baeza ${ }^{120}$, con el fin de tener más fácil acceso a las reparaciones y evitar sustracciones sin licencia. Sin embargo, en Fernán Núñez se dispone bajo los inmuebles,

\footnotetext{
111 Vitrubio, 1997, 212.

112 Pseudo-Juanelo, 1983, 156 y 289.

113 En unas obras recientes de la plaza de Armas se halló una infraestructura anexa al mesón que se ha querido identificar con un aljibe pero que debe ser la antigua galería que desde este establecimiento se conducía el agua al palacio.

Según la tradición oral había un supuesto túnel desde el sótano del mesón a los bajos de la capilla de Santa Escolástica del palacio (coincidiendo con la antigua pared de la plaza, donde estaban las fuentes) así como un hipotético sótano en el subsuelo del actual salón principal de dicho establecimiento. Berral Baena, 2016, 52.

114 AHN-SN, Fernán Núñez, 2250, 5.

115 Vitrubio, 1997, 214.

116 Pseudo-Juanelo, 1983, 151.

117 Córdoba de la Llave y Castillo Pérez de Siles, 1999, 33.

118 Pizarro Berengena, 2012, 198.

119 AHN-SN, Fernán Núñez, 2250, 5.

${ }^{120}$ Cruz Cabrera, 1996, 49.
} 
lo que viene a confirmar una vez más su antigüedad, siendo anterior a las construcciones populares.

Esta infraestructura disfrutó constantemente de una cuidadosa manutención. Actualmente está en desuso, aunque estuvo funcionando hasta 1985 aproximadamente ${ }^{121}$. Cuando en 1983 el ayuntamiento adquirió el palacio y su sistema de abastecimiento, como se expresó más arriba, la competencia del uso de las aguas pasó a manos de la administración municipal, a lo que se unió la ley de $1985^{122}$ que hizo pública la gestión del agua subterránea. El ayuntamiento intentó recuperar el caudal de esta conducción, pero las obras de canalización hacia la localidad originaron problemas, según la sesión extraordinaria de 17 de febrero de $1984^{123}$. Al parecer, el propietario del suelo donde se encuentra el venero exigía más agua de la que se ofrecía ${ }^{124}$. Ante esto, se decidió hacer un pozo más arriba, de $75 \mathrm{~m}$. de profundidad por 40 $\mathrm{cm}$. de diámetro, perdiéndose la anterior arquita y con ello el agua de la Casa Ducal ${ }^{125}$.

\section{CONCLUSIONES}

El estudio de este sistema de abastecimiento nos permite observar que, aunque su origen pudo ser muy anterior, su similitud con otras construcciones locales de finales del siglo XVII y XVIII determinan su reaprovechamiento en esta época. Su principio, no obstante, se encuentra en el suministro del palacio y su jardín y en la necesidad de unificar las aguas locales con el fin de dotar a los molinos de agua, batán e irrigar las nuevas huertas (infraestructuras que tienen su fundación a partir de 1679) lo que explicaría que se descubriera y explotara nuevamente esta red, mejorándola y ampliándola.

Su disposición por debajo de las viviendas urbanas y no por el viario público indicaría igualmente su antigüedad y la del palacio. Éste, aunque se configura nuevamente a finales del siglo XVIII, se alza sobre los restos de construcciones que se superponen sucesivamente desde época romana.

Esta red, por tanto, fue el inicio de este emplazamiento y el motor de una serie de ingenios que no solo dieron origen a la villa, sino que permitieron su enriquecimiento y evolución, manteniéndose hasta casi el final del siglo $\mathrm{XX}$.

Por los motivos expuestos, y viendo el lamentable estado de conservación de algunas de las partes visibles del sistema de abastecimiento del palacio (especialmente la arquería y la arquita de agua) se hace necesaria su difusión con el fin de protegerlo y establecer, también, la propiedad del mismo.

En este aspecto, fue registrado como tal en $1911^{126} \mathrm{y}$ según las escrituras de 21 de julio de 1983 de la cesión del inmueble al ayuntamiento, forman parte del conjunto

\footnotetext{
121 Crespín Cuesta, 1994, 24. 2007, 80.

122 «Este planteamiento impone, por tanto, como novedad la inclusión en el dominio público de las aguas subterráneas, desapareciendo el derecho a apropiárselas que concedía la Ley de 1879 a quien las alumbrase». Ley 29/1985, Boletín Oficial del Estado, 189, 8 de agosto de 1985, 25123.

123 Redacción, 1984, 15.

124 Redacción, 1985, 5-6.

125 Información consultada al servicio de aguas del Ayuntamiento.

126 AHN-SN, Fernán Núñez, 2250, 5.
}

palatino el sistema de cañerías-acueducto que viene desde la estacada de la Peñuela ${ }^{127}$. Por consiguiente, como elemento integrante del edificio, actualmente de propiedad municipal y declarado conjunto histórico-artístico el 13 de julio de 1983, debe ser protegido según el artículo 44 de la Ley de Patrimonio Histórico Español de 1985 que especifica que entraría dentro de la declaración de protección “el hallazgo de partes integrantes de la estructura arquitectónica de un inmueble incluido en el Registro de Bienes de Interés Cultural”.

\section{FUENTES DOCUMENTALES}

Archivo Histórico de Protocolos de Madrid.

Archivo Histórico Provincial de Córdoba.

Archivo Histórico Nacional - Consejos y Sección Nobleza.

Archivo Municipal de Fernán Núñez, Fondo Palacio Ducal.

Archivo Museo Naval de Madrid.

BANC MS UCB 143, Colección Fernán Núñez, Bancroft Library, University of California, Berkeley.

Boletín Oficial del Estado.

Fundación Biblioteca Manuel Ruiz Luque.

\section{BIBLIOGRAFÍA}

AA.VV. 1992: Los pueblos de Córdoba. 2. Córdoba, Caja Provincial de Ahorros de Córdoba.

Añón, C., Luengo, M. y Luengo, A. 2000: Tesoros de España: Jardines Artísticos. 6. Madrid, Espasa Calpe.

Ardemans, T. 1724: Fluencia de la Tierra y curso subterráneo de las aguas. Madrid, Imprenta de Francisco del Hierro.

Artola Blanco, M. 2013: "Crisis y transformación del rentismo agrario. La Casa de Fernán Núñez (1930-1955)”, en XIV Congreso de Historia Agraria, Badajoz, s. p.

Berni y Català, J. 1769: Creación, Antigüedad y Privilegios De los Títulos de Castilla. Valencia, Imprenta particular del autor, 1769.

Berral Baena, A. 2016: "El Mesón del Duque o La Tercia, $1^{\text {a }}$ parte (1/3)", Revista de Feria, 50-54.

Cardozo Uzcátegui, A. 2011: “Don Gerónimo Enrique de Uztáriz y Tovar. II Marqués de Uztáriz. Protector y maestro de Simón Bolívar en Madrid”, Presente y Pasado. Revista de Historia, 31, 11-36.

Conde de Fernán Núñez. 1898: Vida de Carlos III. I y II. Madrid, Librería de los Bibliófilos.

Conde de Fernán Núñez. 1988: Vida de Carlos III. Madrid. Edición de A. Morel Fatio y A. Paz y Melia.

Córdoba de la Llave, R. y Castillo Pérez de Siles, F. 1999: Fuentes de la Provincia de Córdoba, Estudios de Medio Ambiente Provincial. 1. Córdoba, Diputación de Córdoba, Delegación de Medio Ambiente y Protección Civil.

Crespín Cuesta, F. Don Antonio Jurado Moreno y la Arqueología en Fernán Núñez. Inédito.

Crespín Cuesta, F. 1982: Piedras y Cruces. Fernán Núñez, edición del autor.

Crespín Cuesta, F. 1994: Historia de la Villa de Fernán Núñez. Córdoba, Diputación Provincial de Córdoba.

Crespín Cuesta, F. 2007: Callejero de la Villa de Fernán Núñez. Fernán Núñez, Ediciones Puerta de la Villa

Cruz Cabrera, J. P. 1996: Las Fuentes de Baeza. Granada, Universidad de Granada.

Diago. 1965: "Preguntamos al Sr. Alcalde y él nos contesta", Revista de Feria, s. p.

Espejo Jiménez, F. M. 2017: “Los molinos del maestro mayor de la catedral de Granada, José Granados de la Barrera, para la Casa de Fernán Núñez (Córdoba)”, Ámbitos, 38, 75-88.

Espinalt y García, B. 1787: Atlante Español o Descripción General de Todo el Reino de España. XII, II. Madrid, Imprenta de González.

${ }^{127}$ AMFN, HC432.1. 
Fernández, F. B. P. 1769: Instrucciones para el bien público y común de la conservación y aumento de las poblaciones y de las circunstancias más essenciales para sus nuevas fundaciones. I. Madrid, Imprenta de la Viuda de Manuel Fernández.

Gutiérrez de los Ríos, M. 1753: Juicio que sobre la Méthodo controvertida de curar los morbos con el uso del agua y limitación de los purgantes formaba el doctor D. Manuel. Madrid, En la Imprenta de Música.

Heredia-Flores, V. M. 2013: “Municipalización y modernización del servicio de abastecimiento de agua en España: el caso de Málaga (18601930)”, Agua y Territorio, 1, 103-118, https://doi.org/10.17561/at.v1i1.1038

Jurado Miranda, A. y otros. 2004: Documento de Presentación de la Agenda 21 Local de Fernán Núñez. Fernán Núñez, Ayuntamiento de Fernán Núñez y Diputación de Córdoba.

Labaig y Sabala, V. F. 1795: Oración Fúnebre que en las solemnes exequias celebradas por el alma del Excelentísimo Señor D. Carlos Joseph Gutiérrez de los Ríos. Madrid, Imprenta de la viuda de don Joaquín Ibarra.

Lacort Navarro, P. J. 1985: “Cereales en Hispania Ulterior: Silos de Época Íbero-Romana en la Campiña de Córdoba”, Habis, 16, Sevilla, 363-385.

Liñán y Heredia, N. J. 1907: "Los mosaicos de Fernán-Núñez: interesante descubrimiento”, Revista de Archivos, Bibliotecas y Museos, XVI, Madrid, 405-410.

López Amo, J. 1997: Las Aguas de Córdoba: descripción del origen y curso de las aguas potables en 1876. Córdoba, Ediciones la Posada.

Marín Almenara, J. y Molero Berral, F. 1992: "Las Fuentes”, Revista de Feria, 75-80.

Naranjo Ramírez, J. 1991a: Cultivos, aprovechamientos y Sociedad Agraria en la Campiña de Córdoba: Fernán Núñez y Montemayor (s. XVIII$X X)$. Córdoba, Concejalías de Cultura de los Ilmos. Ayuntamiento de Fernán Núñez y Montemayor y Áreas de Geografía de la Universidad de Córdoba.

Naranjo Ramírez, J. 1991b: La propiedad agraria en dos señoríos cordobeses: Fernán Núñez y Montemayor. Córdoba, Servicio de Publicaciones de la Universidad de Córdoba.

Naranjo Ramírez, J. 1992: “Acerca de la burguesía agraria: el caso de Fernán Núñez (Córdoba)”, Ifigea: revista de la Sección de Geografía e Historia, 7-8, 163-187.
Naranjo Ramírez, J. 1995: "Peculiar organización agraria de un señorío en la Campiña de Córdoba: Fernán Núñez”, en VV. AA. Andalucía Moderna: actas del II Congreso de Historia de Andalucía: Córdoba, 1991, VIII. Córdoba, Publicaciones del Monte de Piedad y Caja de Ahorros de Córdoba 139-150.

Pizarro Berengena, G. 2012: El abastecimiento de agua a Córdoba. Arqueología e Historia. Córdoba, Servicio de Publicaciones de la Universidad de Córdoba.

Plinio, 2002: Historia Natural, XXXI, Madrid, Ediciones Cátedra.

Pseudo-Juanelo Turriano. 1983: Los veintiún libros de los ingenios y las máquinas. Madrid, Ediciones Turner.

Ramírez y Las Casas-Deza, L.M. 1986: Corografía Histórico-Estadística de la Provincia y Obispado de Córdoba. Córdoba, Publicaciones del Monte de Piedad y Caja de Ahorros de Córdoba.

Redacción. 1984: “Acuerdos más importantes de la Corporación Municipal (Diciembre 83-Marzo 84)”, La Graílla, 6, 14-15

Redacción. 1985: “Sala de Sesiones”, La Graílla, 11-12, 4-6.

Ríos y Córdoba, F. 1680: El Hombre Práctico. Bruselas, s. e.

Sánchez de Feria y Morales, B. 1762: Compendio de la vida, virtudes, y milagros del Apóstol del Perú San Francisco Solano, del Sagrado Orden de San Francisco, y Patrono de la Ciudad de Montilla: con notas, y reflexiones críticas, sobre los principales sucessos de la Historia. Madrid, En la imprenta de Miguel Escrivano.

Sánchez de Feria y Morales, B. 1772: Palestra Sagrada o Memorial de Santos de Córdoba: con notas y reflexiones críticas sobre los principales sucesos de sus Historias. IV. Córdoba, en la Oficina de Juan Rodríguez.

Sánchez Trigueros, J. A. 2000: Tesoros de España: Fuentes. 11. Madrid, Espasa Calpe.

Sarazá Murcia, A. 1935: Por tierras de Andalucía. La Provincia de Córdoba. Córdoba, Imprenta Provincial.

Vigara Zafra, J. A. 2015: Arte y Cultura Nobiliaria en la Casa de Fernán Núñez (1700-1850), tesis doctoral, UNED, Madrid.

Vitrubio, 1997: Los diez libros de arquitectura. Madrid, Alianza Forma.

Zurita, A. 1951: "Efemérides”, Revista de Feria, s. p. 